Supporting Information

\title{
Chemical Aging Changed Aggregation Kinetics and Transport of Biochar Colloids
}

Yang Wang, Wei Zhang ${ }^{\mathrm{b}}$, Jianying Shang*, a Chongyang Shen ${ }^{\mathrm{a}}$, and Stephen D. Joseph $^{\mathrm{c}}$.

${ }^{\text {a }}$ College of Resources and Environmental Sciences, China Agricultural University, Key Laboratory of Plant-Soil Interactions, Ministry of Education, and Key Laboratory of Arable Land Conservation (North China), Ministry of Agriculture, Beijing 100193, China

${ }^{\mathrm{b}}$ Department of Plant, Soil and Microbial Sciences; and Environmental Science and Policy Program, Michigan State University, East Lansing, Michigan 48824, United

States

c School of Materials Science and Engineering, University of new South Wales, Kensington NSW 2052, Australia

* Corresponding author: Tel.: +86 10 62733509; Fax: +86 10 62733509; E-mail: jyshang@cau.edu.cn

Submitted to Environmental Science \& Technology

The Supporting Information including 29 pages,15 figures, and 7 tables 


\begin{tabular}{|c|c|}
\hline \multicolumn{2}{|l|}{ Content } \\
\hline Title & Page \\
\hline S1.Transport model & S3-S4 \\
\hline S2. The interaction energy of pristine and aged biochar colloids with sand & S5-S6 \\
\hline Table S1.The common elemental contents of biochars. & S7 \\
\hline Table S2.XPS results of PB300 and aged PB300. & S8 \\
\hline Table S3.XPS results of PB600 and aged PB600. & S9 \\
\hline $\begin{array}{l}\text { Table S4.Contact angle measurements, surface tension components, } \\
\text { Hamaker constant for pristine and aged biochar particles. }\end{array}$ & S10 \\
\hline $\begin{array}{l}\text { Table S5.Critical coagulation concentration (CCC) of pristine and aged } \\
\text { PB300 and PB600 colloids under different electrolyte solution conditions. }\end{array}$ & S11 \\
\hline $\begin{array}{l}\text { Table S6.The mass balance percentages of biochar colloids in the column } \\
\text { experiments. }\end{array}$ & S12 \\
\hline $\begin{array}{l}\text { Table S7.Fitted transport parameters in the column experiments of pristine } \\
\text { and aged biochar colloids using the two-site kinetic retention model. }\end{array}$ & $\mathrm{S} 13$ \\
\hline $\begin{array}{l}\text { Figure S1.Measured and fitted breakthrough curve of tracer }\left(\mathrm{NO}_{3}{ }^{-}\right) \text {as a } \\
\text { function of pore volume in the column experiment. }\end{array}$ & S14 \\
\hline $\begin{array}{l}\text { Figure S2.UV-Vis calibration curves of (a) PB300, (b) Aged PB300, (c) } \\
\text { PB600 and (d) Aged PB600 colloids in } 1 \mathrm{mM} \mathrm{NaCl} \text { solutions. }\end{array}$ & $\mathrm{S} 15$ \\
\hline $\begin{array}{l}\text { Figure S3.C1s region scan of (a) PB300, (b) Aged PB300, (c) PB600, and } \\
\text { (d) Aged PB600 by XPS. }\end{array}$ & S16 \\
\hline $\begin{array}{l}\text { Figure S4.Proportion (\%) of different functional groups as identified in } \\
\text { XPS C1s for surface of pristine and aged biochar. }\end{array}$ & $\mathrm{S} 17$ \\
\hline $\begin{array}{l}\text { Figure S5.Hydrodynamic diameter distribution and TEM images for (a) } \\
\text { PB300, (b) Aged PB300, (c) PB600, and (d) Aged PB600 colloids. }\end{array}$ & S18 \\
\hline Figure S6.AFM images of PB300 and Aged PB300. & S19 \\
\hline Figure S7.AFM images of PB600 and Aged PB600. & $\mathrm{S} 20$ \\
\hline $\begin{array}{l}\text { Figure S8.Zeta potentials of pristine and aged PB300 and PB600 colloids } \\
\text { as a function of } \mathrm{pH} \text { in } 1 \mathrm{mM} \mathrm{NaCl} \text { solution at } 25^{\circ} \mathrm{C} \text {. }\end{array}$ & S21 \\
\hline $\begin{array}{l}\text { Figure S9.Aggregation profiles of pristine and aged } \mathrm{PB} 300 \text { and } \mathrm{PB} 600 \text { in } \\
\mathrm{NaCl} \text { solution at } \mathrm{pH} 6.5 \text {. }\end{array}$ & S22 \\
\hline $\begin{array}{l}\text { Figure S10.Aggregation profiles of pristine and aged PB300 and PB600 in } \\
\mathrm{CaCl}_{2} \text { solution at } \mathrm{pH} \text { 6.5. }\end{array}$ & S23 \\
\hline $\begin{array}{l}\text { Figure S11.Zeta potential of pristine and aged PB300 and PB600 colloids } \\
\text { as a function of (a) } \mathrm{NaCl} \text { and (b) } \mathrm{CaCl}_{2} \text { concentration at pH } 6.5 \text {. }\end{array}$ & S24 \\
\hline $\begin{array}{l}\text { Figure S12.Representative TEM images for pristine and aged PB300 and } \\
\text { PB600 colloids in } 600 \mathrm{mM} \mathrm{NaCl} \text { at } \mathrm{pH}=6.5 \text {, respectively. }\end{array}$ & S25 \\
\hline $\begin{array}{l}\text { Figure S13.Representative TEM images for (a) PB300, (b) Aged PB300, } \\
\text { (c) PB600, and (d) Aged PB600 colloids in } 60 \mathrm{mM} \mathrm{CaCl}_{2} \text { at pH=6.5. }\end{array}$ & S26 \\
\hline Figure S14.Fluorescence EEMs for pristine and aged biochar. & $\mathrm{S} 27$ \\
\hline $\begin{array}{l}\text { Figure S15.XDLVO interaction energy profiles for pristine and aged } \\
\text { biochar colloids and sand interactions for in } \mathrm{NaCl} \text { and } \mathrm{CaCl}_{2} \text { solutions. }\end{array}$ & S28 \\
\hline References & S29 \\
\hline
\end{tabular}




\section{S1. Transport Model}

The transport of both pristine and aged biochar colloids at a steady-state flow condition was simulated using a convection-dispersion equation with a two-site kinetic retention model. ${ }^{1,2}$

$$
\frac{\partial(\theta C)}{\partial \mathrm{t}}+\rho_{b} \frac{\partial\left(S_{1}\right)}{\partial \mathrm{t}}+\rho_{b} \frac{\partial\left(S_{2}\right)}{\partial \mathrm{t}}=\frac{\partial}{\partial x}\left(\theta D \frac{\partial C}{\partial x}\right)-\frac{\partial q C}{\partial x}
$$

where $\theta$ is the volumetric water content, $C$ is the concentration of biochar colloids in the aqueous phase, $t$ is the time, $\rho_{b}$ is the bulk density of the porous media, $x$ is the vertical spatial coordinate, $D$ is the hydrodynamic dispersion coefficient $\left(0.0043 \mathrm{~cm}^{2}\right.$ $\min ^{-1}$ estimated by the breakthrough curve of nitrate tracer in our experiment), $q$ is the Darcy velocity, and $S_{1}$ and $S_{2}$ are the solid phase concentrations associated with the kinetic retention site 1 and site 2, respectively. Here we assume that the reversible kinetic retention occurs at site 1 and the depth-dependent irreversible kinetic retention occurs at site 2:

$$
\begin{gathered}
\rho \frac{\partial\left(S_{1}\right)}{\partial \mathrm{t}}=\theta k_{1} c-k_{1 d} \rho_{\mathrm{b}} S_{1} \\
\rho \frac{\partial\left(S_{2}\right)}{\partial \mathrm{t}}=\theta k_{2}\left(\frac{\mathrm{d}_{c}+x-x_{0}}{\mathrm{~d}_{c}}\right)^{-\beta} c
\end{gathered}
$$

where $k_{1}$ and $k_{2}$ are the first-order retention coefficients at site 1 and 2, respectively, $k_{1 d}$ is the first-order detachment coefficient at site $1, \mathrm{~d}_{c}$ is the diameter of the sand grains, $x_{0}$ is the coordinate of the column inlet, and $\beta$ is an empirical factor (with an optimal value of 0.432$){ }^{1}\left(\frac{\mathrm{d}_{c}+x-x_{0}}{\mathrm{~d}_{c}}\right)^{-\beta}$ denotes a dimensionless colloid retention function at site 2 that is well suited to describe the depth-dependent straining of colloids. ${ }^{1,3}$ This retention function can best describe both the breakthrough curves and retention profiles of pristine and aged biochar colloids in our study. The other functions such as Langmuirian blocking ${ }^{4}$ and random sequential adsorption ${ }^{5}$ cannot 
describe the transport behaviors of biochar colloids. The hydrodynamic dispersion coefficient was calculated through fitting tracer breakthrough curves and the other parameters $\left(k_{1}, k_{1 d}\right.$, and $\left.k_{2}\right)$ of pristine and aged biochar colloids were obtained by fitting the breakthrough curves and retention profiles of biochar colloids using the HYDRUS-1D code. ${ }^{6}$ 


\section{S2. The interaction energy of pristine and aged biochar colloids with sand}

In order to quantitatively explain the effect of chemical aging on the transport of biochar colloid under different cationic types $\left(\mathrm{Na}^{+}\right.$and $\left.\mathrm{Ca}^{2+}\right)$, the extended Derjaguin-Landau-Verwey-Overbeek (XDLVO) theory was used to calculate the interaction between biochar colloids and quartz sand surface. The total energy of colloids-sand system included Lifshitz-van der Waals (LW), the electrostatic double layer (EDL), and the Lewis acid-base (AB) interactions. The equations ${ }^{7-9}$ are listed as follows:

$$
\begin{gathered}
\Phi_{\text {total }}=\Phi_{L W}+\Phi_{E D L}+\Phi_{A B} \\
\Phi_{L W}=-\frac{A r}{6 h}\left[1-\frac{5.32 h}{\lambda_{0}} \ln \left(1+\frac{\lambda_{0}}{5.32 h}\right)\right] \\
\Phi_{E D L}=\pi \varepsilon_{0} \varepsilon_{w} r\left\{2 \varphi_{1} \varphi_{2} \ln \left[\frac{1+\exp (-\kappa h)}{1-\exp (-\kappa h)}\right]+\left(\varphi_{1}^{2}+\varphi_{2}^{2}\right) \ln [1-\exp (-2 \kappa h)]\right\} \\
\Phi_{A B}=2 \pi r \lambda_{w} \Delta G_{h_{0}, A B} \exp \left(\frac{h_{0}-h}{\lambda_{w}}\right) \\
\kappa=\sqrt{\frac{e^{2} \sum_{i} n_{i} z^{2}}{\varepsilon_{0} \varepsilon_{w} k T}}
\end{gathered}
$$

where $A$ is the Hamaker constant $(\mathrm{J})$ and the values of $A$ is $4.42 \times 10^{-20} \mathrm{~J}^{10} r$ represents the radius of biochar colloids (m); $\mathrm{h}$ is the parameter for the separation distance between the biochar colloids and the quartz sand surface (m); $\lambda_{0}$ is assumed to be $1 \times 10^{-7} \mathrm{~m}$, which on behalf of the characteristic wavelength of the interaction $(\mathrm{m})$; $\varepsilon_{0}$ is the dielectric permittivity of vacuum $\left(\mathrm{F} \mathrm{m}^{-1}\right) ; \varepsilon_{\mathrm{w}}$ is the dielectric constant of water $\left(\mathrm{F} \mathrm{m}^{-1}\right) ; \varphi_{1}$ and $\varphi_{2}$ are the zeta potentials (V) of the biochar colloids and quartz sand, respectively; $\kappa$ is the Debye-Hückel reciprocal length $\left(\mathrm{m}^{-1}\right)$; $h_{0}$ is the value for the minimum equilibrium distance to which two condensed-phase surfaces can approach 
one another $(\mathrm{m})$, the value of $h_{0}$ is assumed as $1.57 \times 10^{-10} \mathrm{~m} ;{ }^{8} e$ is the elementary charge (C); $n$ is the number concentration of ions in the bulk suspension; $z$ is the valence of ion in the bulk suspension; $k$ is the Boltzmann constant $\left(\mathrm{J} \mathrm{K}^{-1}\right)$; $T$ is the absolute temperature $(\mathrm{K}) ; \lambda_{w}$ is the characteristic decay length of $\mathrm{AB}$ interactions in water (m), at $20^{\circ} \mathrm{C}, \lambda_{w}=10^{-9} \mathrm{~m}$; and $\Delta G_{h 0, A B}$ represents the AB interaction free energy per unit area corresponding to $h_{0}$, which is determined through the contact angles of the biochar. ${ }^{8}$ 
Table S1. Surface elemental composition and atomic ratio of pristine and aged biochar samples measured by XPS.

\begin{tabular}{|c|c|c|c|c|c|c|c|c|c|}
\hline \multirow[t]{2}{*}{ Biochars } & \multicolumn{7}{|c|}{ Elemental content \% } & \multicolumn{2}{|c|}{ Atomic ratio } \\
\hline & $\mathrm{C}$ & $\mathrm{O}$ & $\mathrm{N}$ & $S$ & $\mathrm{Ca}$ & $\mathrm{Na}$ & $\mathrm{Si}$ & $\mathrm{O} / \mathrm{C}$ & $(\mathrm{O}+\mathrm{N}) / \mathrm{C}$ \\
\hline PB300 & 78.6 & 18.8 & 1.6 & 0.3 & 0.2 & 0.1 & 0.5 & 0.24 & 0.26 \\
\hline Aged PB300 & 66.3 & 29.3 & 2.1 & 0.1 & 0.2 & 0.1 & 1.9 & 0.44 & 0.47 \\
\hline PB600 & 86.4 & 12.0 & 0.9 & 0.1 & 0.3 & 0.1 & 0.2 & 0.14 & 0.15 \\
\hline Aged PB600 & 77.4 & 16.8 & 4.7 & 0.1 & 0.1 & 0.1 & 0.7 & 0.22 & 0.28 \\
\hline
\end{tabular}


Table S2. XPS results of PB300 and aged PB300.

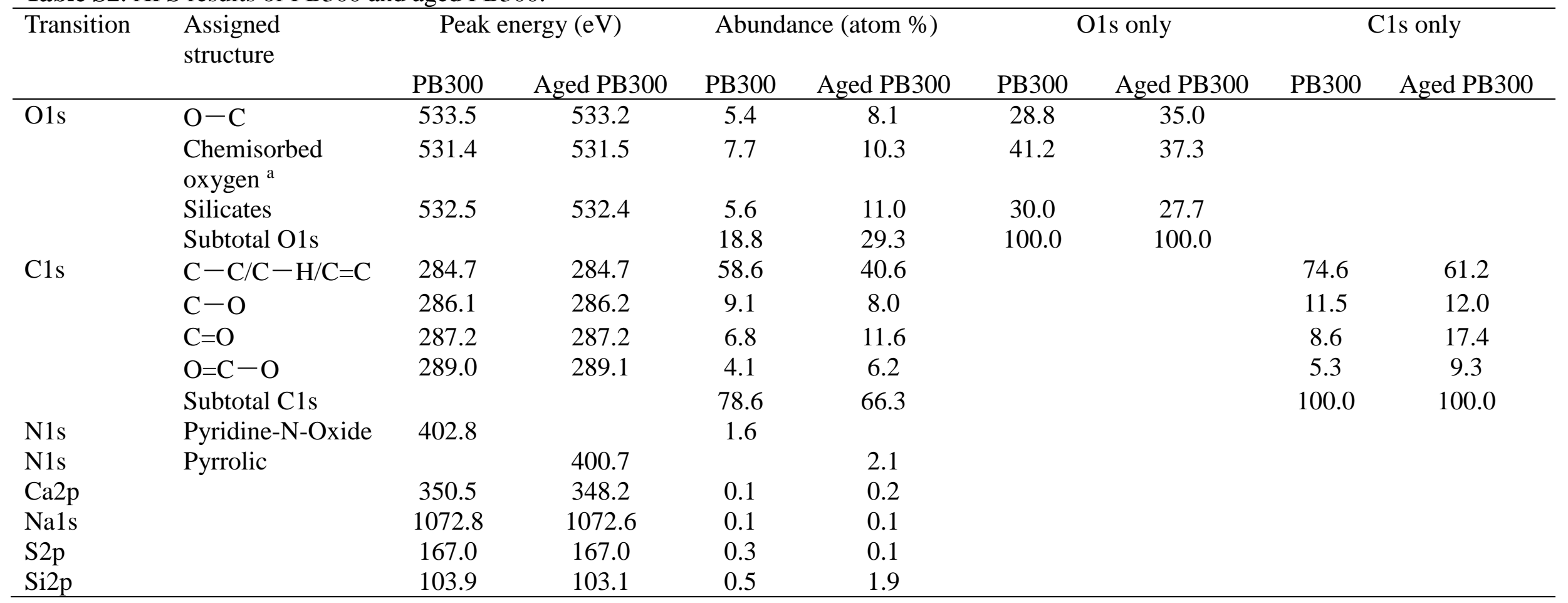


Table S3. XPS results of PB600 and aged PB600.

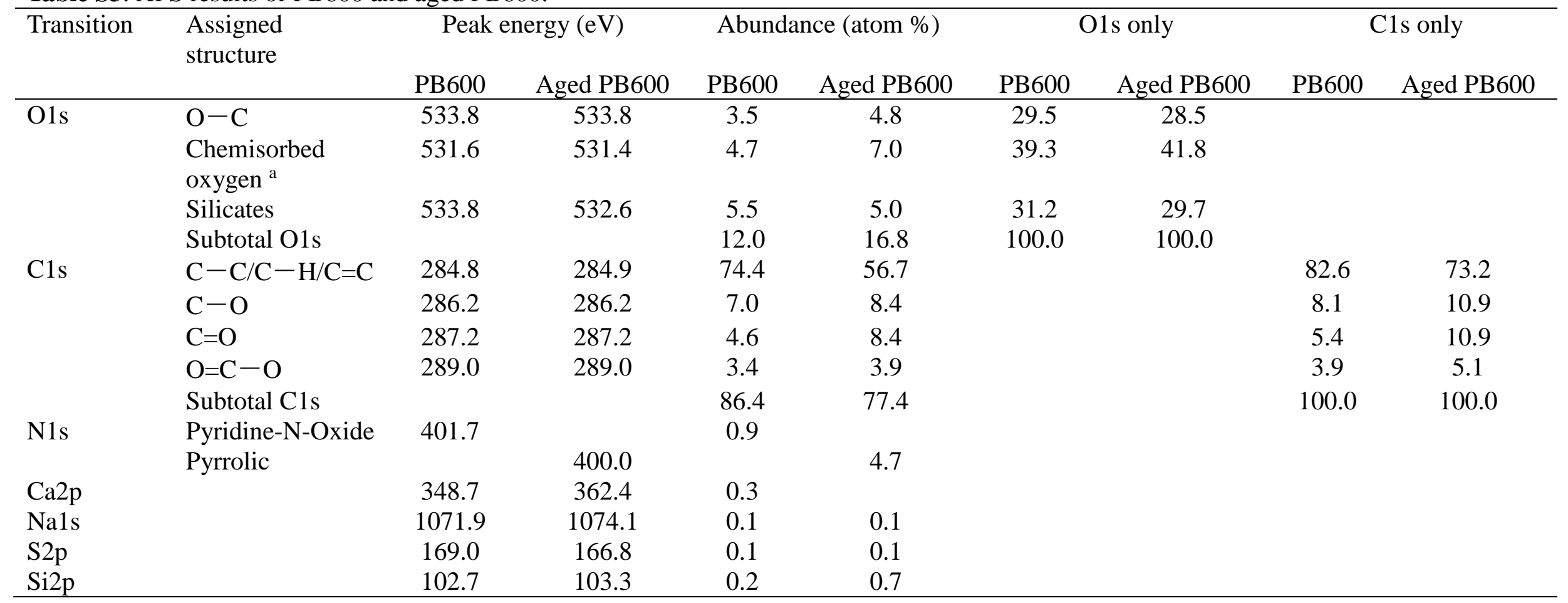


Table S4 Contact angle measurements, surface tension components, Hamaker constant for pristine and aged biochar particles.

\begin{tabular}{cccccc}
\hline Properties & & PB300 & Aged PB300 & PB600 & Aged PB600 \\
\hline contact angle $\left(^{\circ}\right)$ & water & 90.5 & 43.0 & 100.5 & 74.5 \\
& glycerol & 92.9 & 72.9 & 92.6 & 77.4 \\
& n-decane & 0 & 0 & 0 & 0 \\
Surface tension & $\gamma^{\mathrm{LW}}$ & 23.8 & 23.8 & 23.8 & 23.8 \\
components $\left(\mathrm{mJ} \mathrm{m}^{-2}\right)$ & $\gamma^{+}$ & 0.34 & 0.25 & $1.30 \times 10^{-2}$ & $2.89 \times 10^{-2}$ \\
& $\gamma^{-}$ & 4.2 & 55.7 & 1.6 & 31.7 \\
Hamaker constant & & & & & \\
$\left(10^{-20} \mathrm{~J}\right)$ & & 4.42 & 4.42 & 4.42 & 4.42 \\
$\Delta G_{h 0, A B}\left(\mathrm{~mJ} \mathrm{~m}^{-2}\right)$ & & -0.01 & 0.04 & -0.01 & 0.02 \\
\hline
\end{tabular}


Table S5. Critical coagulation concentration (CCC) of pristine and aged PB300 and PB600 colloids under different electrolyte solution conditions.

\begin{tabular}{ccc}
\hline Colloids & \multicolumn{2}{c}{ Background solutions } \\
\cline { 2 - 3 } & $\mathrm{NaCl}(\mathrm{mM})$ & $\mathrm{CaCl}_{2}(\mathrm{mM})$ \\
\hline PB300 & $300.4 \pm 4.2$ & $58.6 \pm 0.8$ \\
Aged PB300 & $540.1 \pm 5.7$ & $25.2 \pm 1.1$ \\
PB600 & $181.5 \pm 1.8$ & $41.7 \pm 2.6$ \\
Aged PB600 & $327.4 \pm 2.6$ & $32.1 \pm 0.5$ \\
\hline
\end{tabular}

As shown in Table S5, the CCCs for pristine and aged PB300 colloids in $\mathrm{CaCl}_{2}$ solutions were 58.6 and $25.2 \mathrm{mM}$, whereas the CCCs for pristine and aged PB600 colloids were 41.7 and $32.1 \mathrm{mM}$, respectively. It is expected that the CCCs of biochar colloids were much lower in $\mathrm{CaCl}_{2}$ solution than their respective CCCs in $\mathrm{NaCl}$ solution because $\mathrm{Ca}^{2+}$ ions have stronger capability of charge screening and neutralization, which further reduce the repulsive energy barrier between colloids. ${ }^{11}$ According to the Schulze-Hardy Rule, colloidal stability is highly related to the electrolyte valence, and electrolytes of higher valence can cause more efficient coagulation. $^{12,13}$ 
Table S6. The mass balance percentages of biochar colloids in the column experiments.

\begin{tabular}{|c|c|c|c|c|c|}
\hline \multirow[t]{2}{*}{ Biochar } & \multicolumn{2}{|c|}{$\begin{array}{c}\text { Ionic strength } \\
\mathrm{mM}\end{array}$} & \multirow[t]{2}{*}{$M_{\mathrm{BTC}}{ }^{\text {a } \%}$} & \multirow[t]{2}{*}{$M_{\mathrm{RET}}{ }^{\mathrm{b}} \%$} & \multirow[t]{2}{*}{$M_{\text {TOT }}{ }^{c} \%$} \\
\hline & $\mathrm{NaCl}$ & $\mathrm{CaCl}_{2}$ & & & \\
\hline PB300 & 10 & & $60.1 \pm 1.0$ & $40.6 \pm 1.2$ & $100.7 \pm 2.2$ \\
\hline Aged PB300 & 10 & & $88.0 \pm 0.9$ & $11.9 \pm 0.8$ & $99.9 \pm 1.7$ \\
\hline PB600 & 10 & & $36.3 \pm 1.8$ & $65.8 \pm 0.7$ & $102.2 \pm 2.5$ \\
\hline Aged PB600 & 10 & & $64.2 \pm 1.1$ & $28.6 \pm 1.2$ & $92.8 \pm 2.3$ \\
\hline PB300 & 50 & & $30.6 \pm 1.2$ & $71.8 \pm 0.5$ & $102.4 \pm 1.7$ \\
\hline Aged PB300 & 50 & & $83.1 \pm 0.2$ & $19.2 \pm 0.5$ & $102.3 \pm 0.7$ \\
\hline PB600 & 50 & & $7.2 \pm 1.1$ & $92.5 \pm 1.2$ & $99.6 \pm 2.3$ \\
\hline Aged PB600 & 50 & & $47.1 \pm 0.5$ & $55.0 \pm 0.3$ & $102.2 \pm 0.8$ \\
\hline PB300 & & 1 & $41.6 \pm 0.7$ & $49.8 \pm 1.3$ & $91.4 \pm 2.0$ \\
\hline Aged PB300 & & 1 & $97.0 \pm 0.5$ & $5.8 \pm 0.8$ & $102.8 \pm 1.3$ \\
\hline PB600 & & 1 & $16.3 \pm 2.1$ & $86.3 \pm 1.7$ & $102.6 \pm 3.8$ \\
\hline Aged PB600 & & 1 & $47.7 \pm 1.5$ & $50.8 \pm 1.1$ & $98.5 \pm 2.6$ \\
\hline PB300 & & 10 & $34.2 \pm 2.0$ & $64.0 \pm 1.1$ & $98.2 \pm 3.1$ \\
\hline Aged PB300 & & 10 & $82.7 \pm 1.2$ & $18.8 \pm 1.6$ & $101.5 \pm 2.8$ \\
\hline PB600 & & 10 & $10.4 \pm 2.0$ & $87.2 \pm 2.1$ & $97.6 \pm 4.1$ \\
\hline Aged PB600 & & 10 & $38.9 \pm 1.8$ & $62.0 \pm 2.1$ & $100.9 \pm 3.9$ \\
\hline
\end{tabular}

a, b,and c $M_{\mathrm{BTC}}, M_{\mathrm{RET}}, M_{\text {TOт }}$ are the mass percentage of biochar colloids recovered from the effluents and retained in the sand, and total percentages of biochar colloids recovered from the column experiments, respectively. 
Table S7. Fitted transport parameters in the column experiments of pristine and aged biochar colloids using the two-site kinetic retention model.

\begin{tabular}{|c|c|c|c|c|c|c|}
\hline \multirow[t]{2}{*}{ Biochars } & \multicolumn{2}{|c|}{ Background solution } & \multirow{2}{*}{$\begin{array}{c}k_{1}{ }^{\mathrm{a}} \\
\left(\min ^{-1}\right)\end{array}$} & \multirow{2}{*}{$\begin{array}{c}k_{1 \mathrm{~d}}{ }^{\mathrm{b}} \\
\left(\min ^{-1}\right)\end{array}$} & \multirow{2}{*}{$\begin{array}{c}k_{2}{ }^{\mathrm{c}} \\
\left(\mathrm{min}^{-1}\right)\end{array}$} & \multirow[t]{2}{*}{$\mathrm{R}^{2 \mathrm{~d}}$} \\
\hline & electrolyte & $\begin{array}{c}\text { IS } \\
(\mathrm{mM})\end{array}$ & & & & \\
\hline PB300 & $\mathrm{NaCl}$ & 10 & 0.0037 & 0.0034 & 0.1031 & $97.8 \%$ \\
\hline Aged PB300 & $\mathrm{NaCl}$ & 10 & 0.0024 & 0.0068 & 0.0192 & $99.6 \%$ \\
\hline PB600 & $\mathrm{NaCl}$ & 10 & 0.0044 & 0.0029 & 0.1953 & $97.8 \%$ \\
\hline Aged PB600 & $\mathrm{NaCl}$ & 10 & 0.0031 & 0.0058 & 0.0727 & $98.0 \%$ \\
\hline PB300 & $\mathrm{NaCl}$ & 50 & 0.0267 & 0.0003 & 0.0827 & $100.0 \%$ \\
\hline Aged PB300 & $\mathrm{NaCl}$ & 50 & 0.0036 & 0.0167 & 0.0334 & $96.5 \%$ \\
\hline PB600 & $\mathrm{NaCl}$ & 50 & 0.0736 & 0.0003 & 0.1004 & $94.3 \%$ \\
\hline Aged PB600 & $\mathrm{NaCl}$ & 50 & 0.0167 & 0.0027 & 0.0736 & $94.4 \%$ \\
\hline PB300 & $\mathrm{CaCl}_{2}$ & 1 & 0.0032 & 0.0029 & 0.1637 & $98.3 \%$ \\
\hline Aged PB300 & $\mathrm{CaCl}_{2}$ & 1 & 0.0006 & 0.0064 & 0.0064 & $99.6 \%$ \\
\hline PB600 & $\mathrm{CaCl}_{2}$ & 1 & 0.0396 & 0.0016 & 0.1911 & $98.6 \%$ \\
\hline Aged PB600 & $\mathrm{CaCl}_{2}$ & 1 & 0.0017 & 0.0050 & 0.1492 & $99.8 \%$ \\
\hline PB300 & $\mathrm{CaCl}_{2}$ & 10 & 0.0274 & 0.0003 & 0.0653 & $98.0 \%$ \\
\hline Aged PB300 & $\mathrm{CaCl}_{2}$ & 10 & 0.0033 & 0.0167 & 0.0334 & $93.4 \%$ \\
\hline PB600 & $\mathrm{CaCl}_{2}$ & 10 & 0.0642 & 0.0003 & 0.1316 & $98.2 \%$ \\
\hline Aged PB600 & $\mathrm{CaCl}_{2}$ & 10 & 0.0221 & 0.0004 & 0.0630 & $94.0 \%$ \\
\hline
\end{tabular}




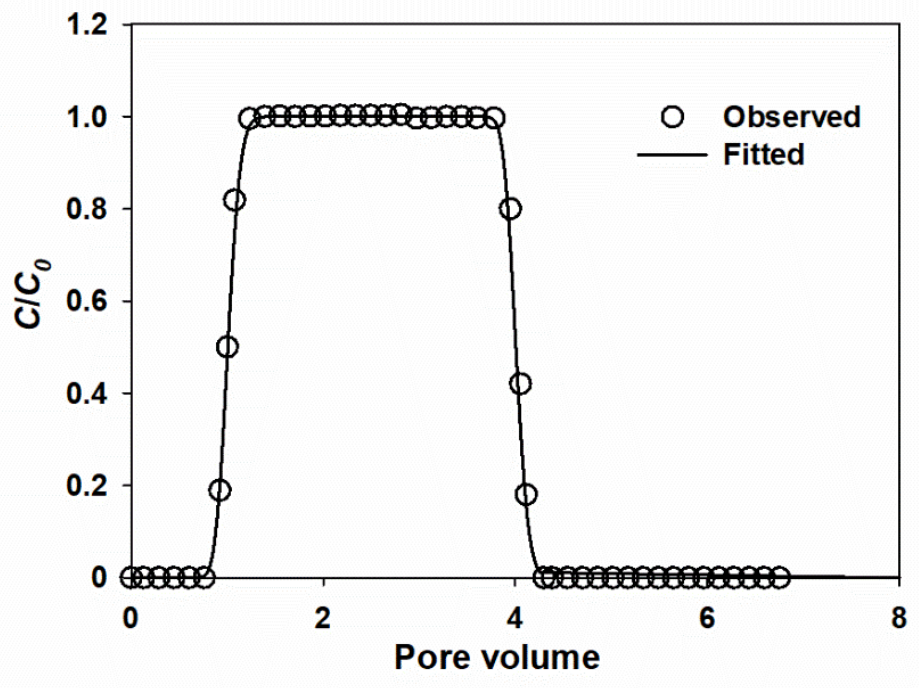

Figure S1. Measured and fitted breakthrough curve of tracer $\left(\mathrm{NO}_{3}{ }^{-}\right)$as a function of pore volume in the column experiment. 

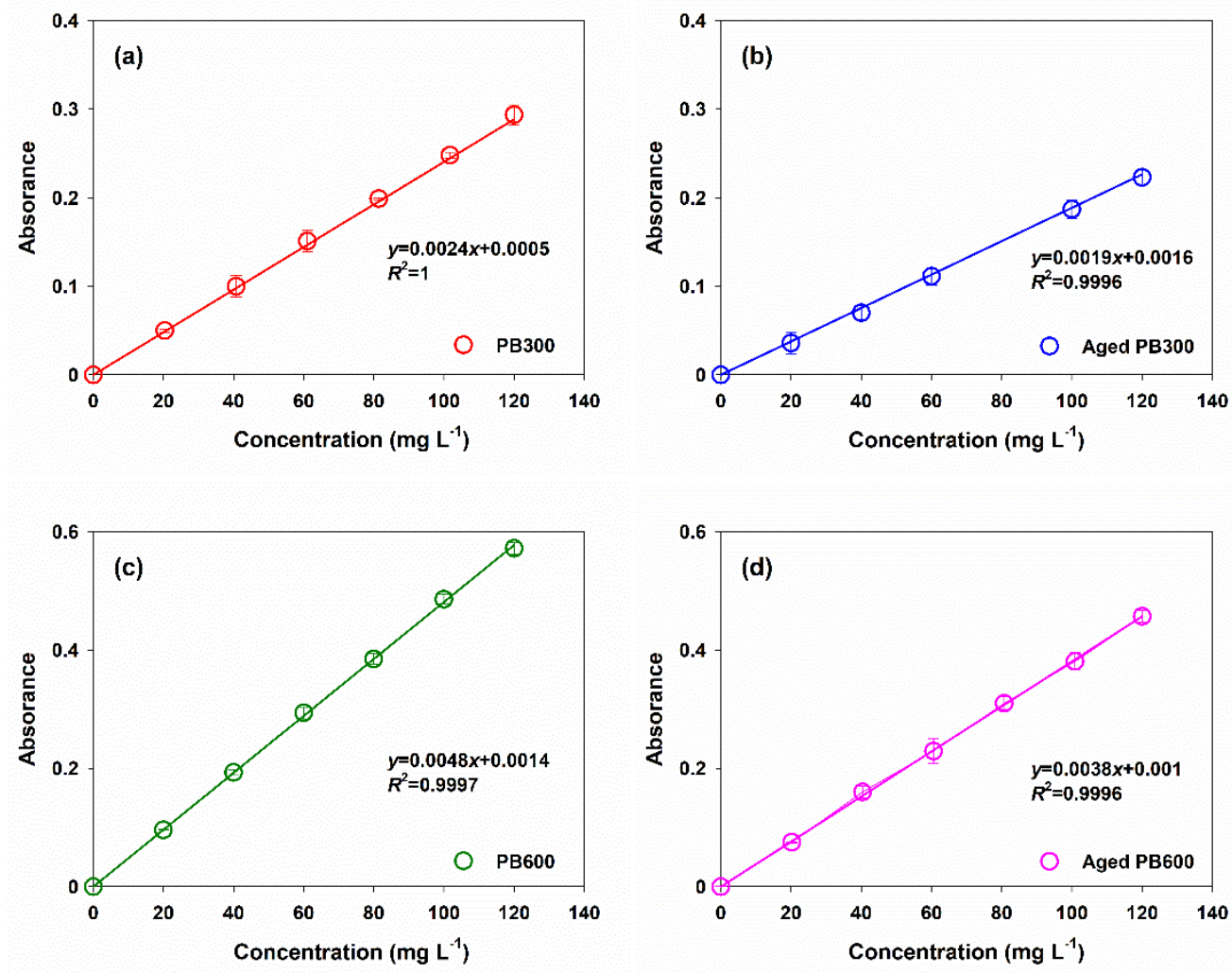

Figure S2. UV-Vis calibration curves of (a) PB300, (b) Aged PB300, (c) PB600, and (d) Aged PB600 colloids in $1 \mathrm{mM} \mathrm{NaCl}$ solutions $\left(0-120 \mathrm{mg} \mathrm{L}^{-1}\right)$. Error bars represent the standard deviations in duplicated experiments. 

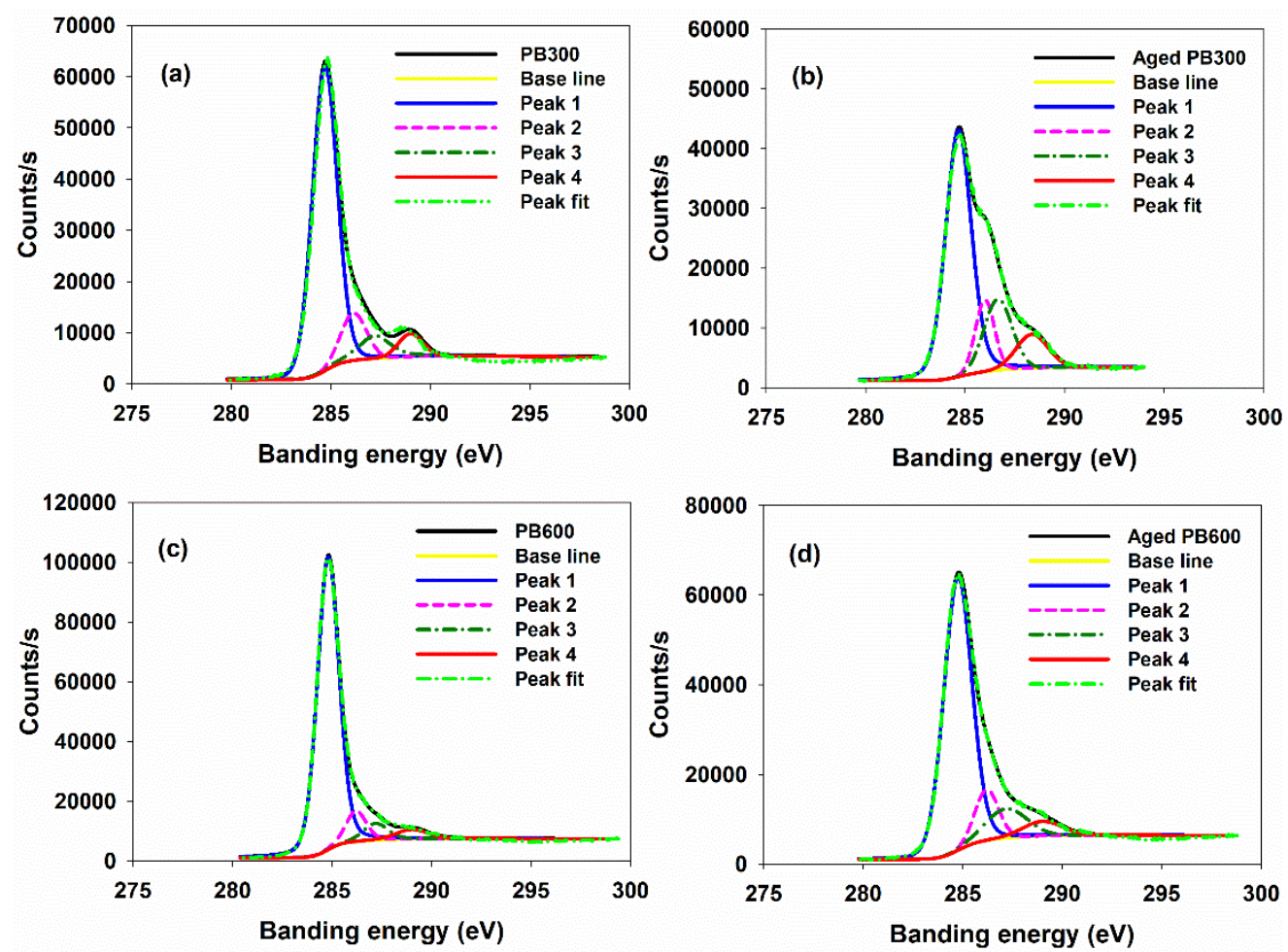

Figure S3. C1s region scan of (a) PB300, (b) Aged PB300, (c) PB600, and (d) Aged PB600 by XPS. The C1s spectra included C-C, C-H, or $\mathrm{C}=\mathrm{C}$ (aromatic carbon) at peak 1 of $\sim 284.6 \mathrm{eV}, \mathrm{C}-\mathrm{O}$ (phenolic hydroxyl or ether group) at peak 2 of $\sim 286.2 \mathrm{eV}$, $\mathrm{C}=\mathrm{O}$ (ketone $\mathrm{C}$ ) at peak 3 of $\sim 287.2 \mathrm{eV}$, and COO (carboxylic group) at peak 4 of $\sim 289.0 \mathrm{eV}$. 


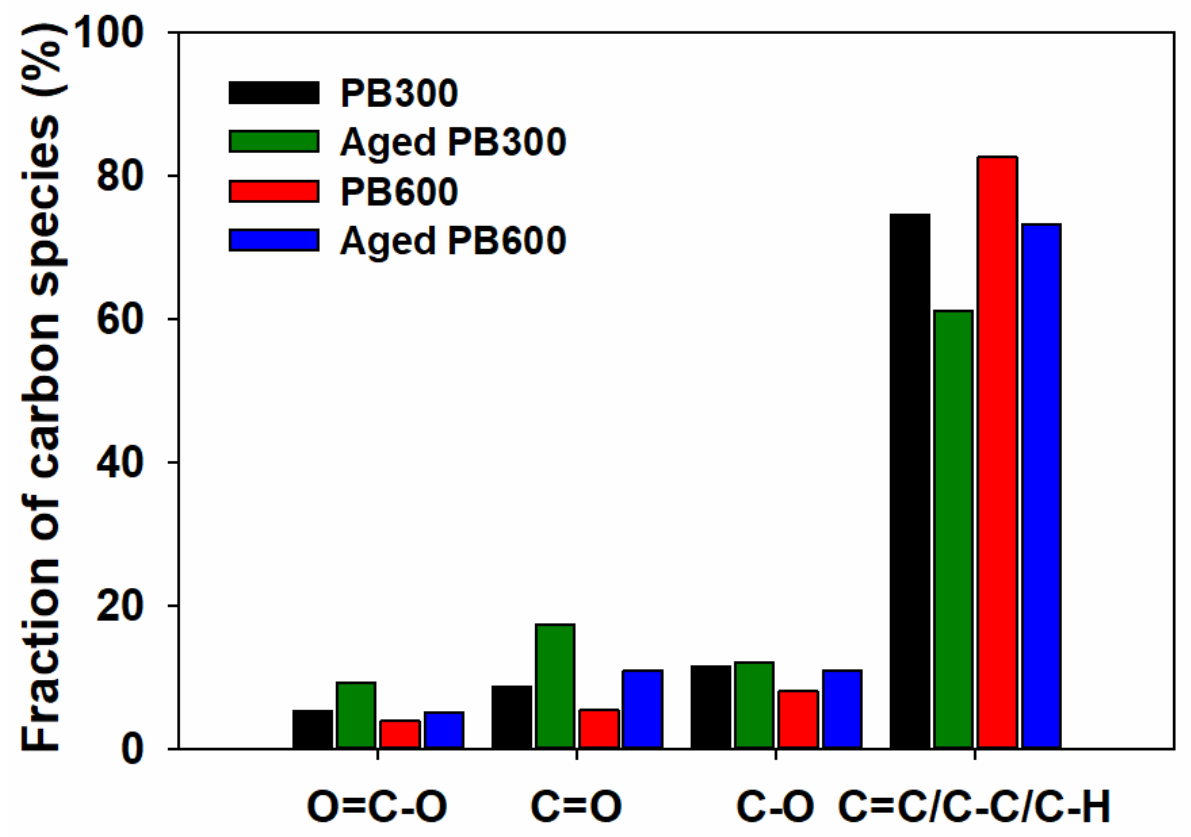

Figure S4. Proportion (\%) of different functional groups as identified in XPS C1s for surface of pristine and aged biochar. 

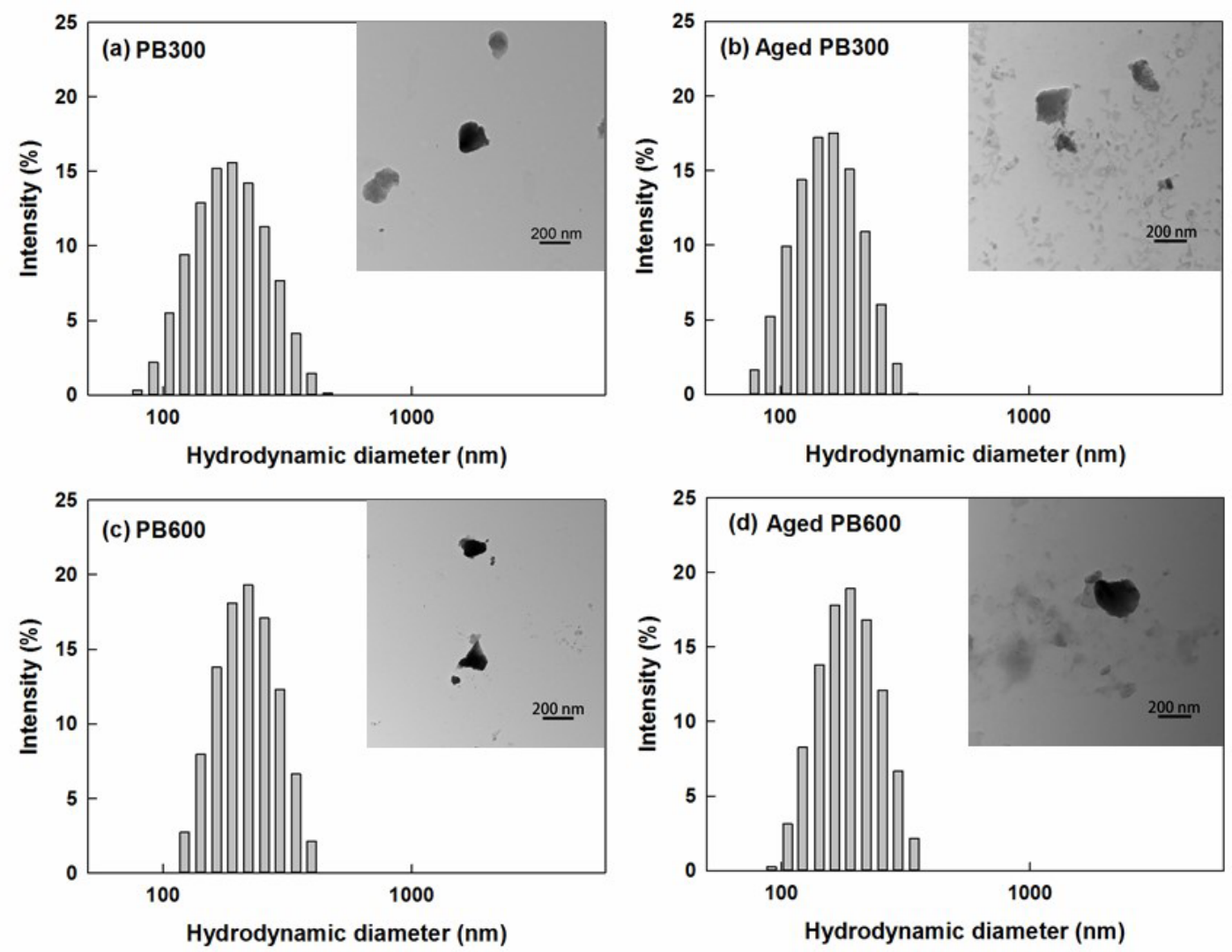

Figure S5. Hydrodynamic diameter distribution and TEM images for (a) PB300, (b) Aged PB300, (c) PB600, and (d) Aged PB600 colloids. Solution pH was adjusted to 6.5 with $\mathrm{HCl} / \mathrm{NaOH}$ at room temperature $25^{\circ} \mathrm{C}$. 

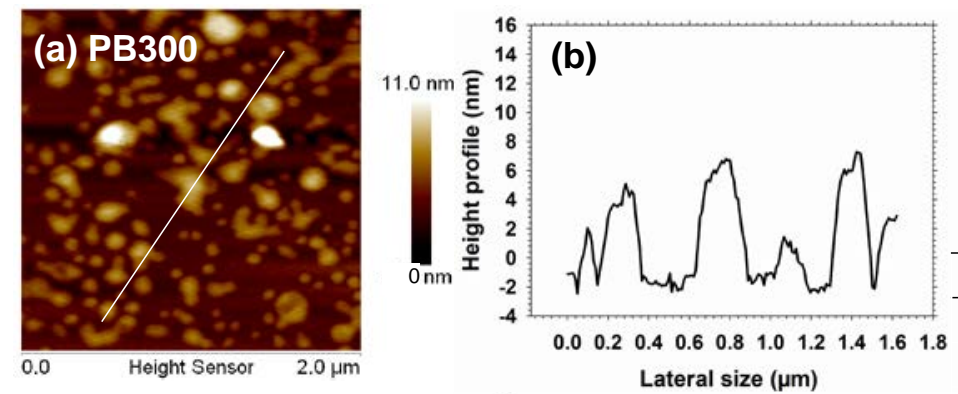

\section{(e)}

\begin{tabular}{ccc}
\hline Biochars & PB300 & Aged PB300 \\
\hline Ra $(n m)^{\mathrm{a}}$ & 5.148 & 10.591 \\
RMS $(\mathrm{nm})^{\mathrm{b}}$ & 1.146 & 1.667
\end{tabular}
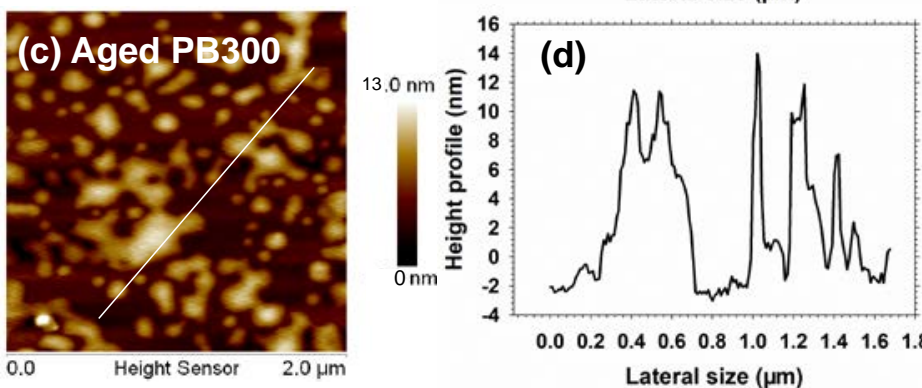

$\begin{array}{lll}\mathrm{Rz}(\mathrm{nm})^{\mathrm{c}} & 3.754 & 7.622\end{array}$

Figure S6. AFM images of (a) PB300 and (c) Aged PB300. The diameter (lateral size, $x$-axis) and thickness (height profile, $y$-axis) analysis of (b) PB300 and (d) Aged PB300 colloids on the line in panel (a) and (c). And the surface roughness analyzed from AFM (e), where are average surface roughness (Ra), root-mean-square roughness (RMS), and 10-point average roughness (Rz) for (a) and (c), respectively. 

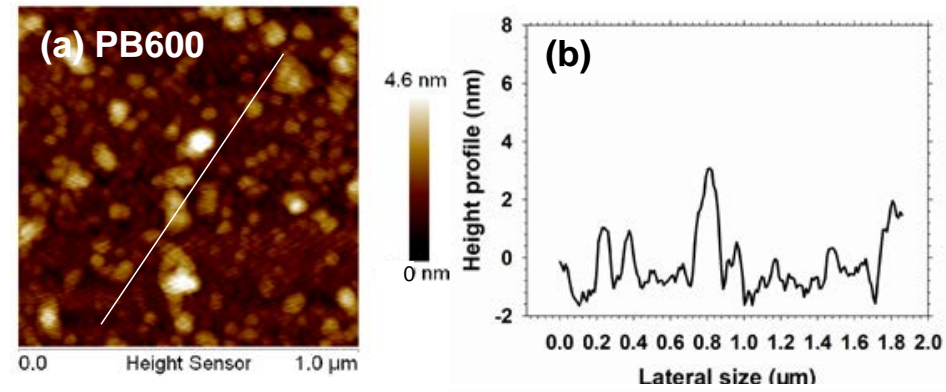

(e)
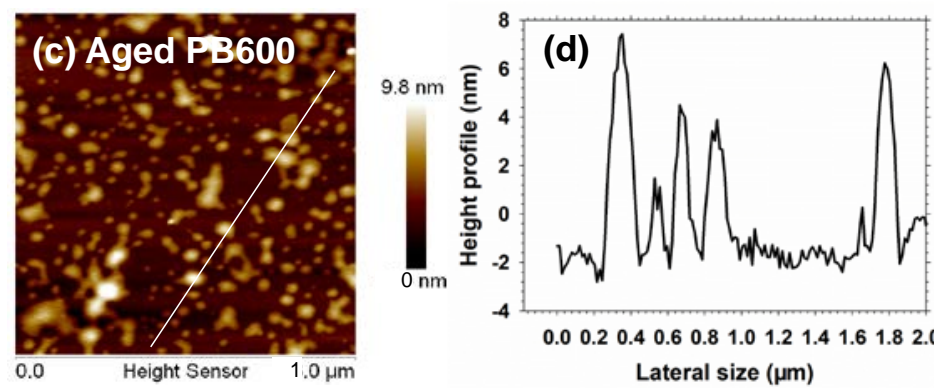

\begin{tabular}{ccc}
\hline Biochars & PB600 & Aged PB600 \\
\hline Ra $(n m)^{\mathrm{a}}$ & 3.105 & 6.343 \\
${\text { RMS }(n m)^{\mathrm{b}}}$ & 0.688 & 1.949
\end{tabular}

Figure S7. AFM images of (a) PB600 and (c) Aged PB600. The diameter (lateral size, $x$-axis) and thickness (height profile, $y$-axis) analysis of (b) PB600 and (d) Aged PB600 colloids on the line in panel (a) and (c). And the surface roughness analyzed from AFM (e), where are average surface roughness (Ra), root-mean-square roughness (RMS), and 10-point average roughness (Rz) for (a) and (c), respectively. 


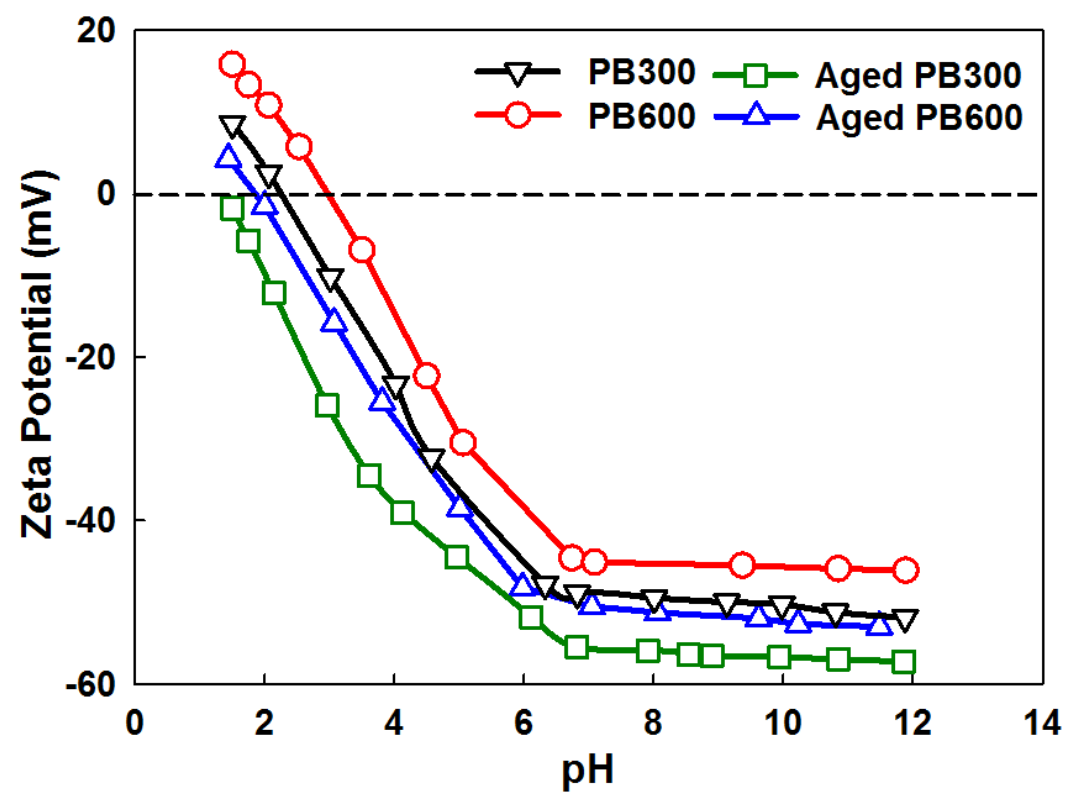

Figure S8. Zeta potentials of pristine and aged PB300 and PB600 colloids as a function of $\mathrm{pH}$ in $1 \mathrm{mM} \mathrm{NaCl}$ solution at $25^{\circ} \mathrm{C}$. 


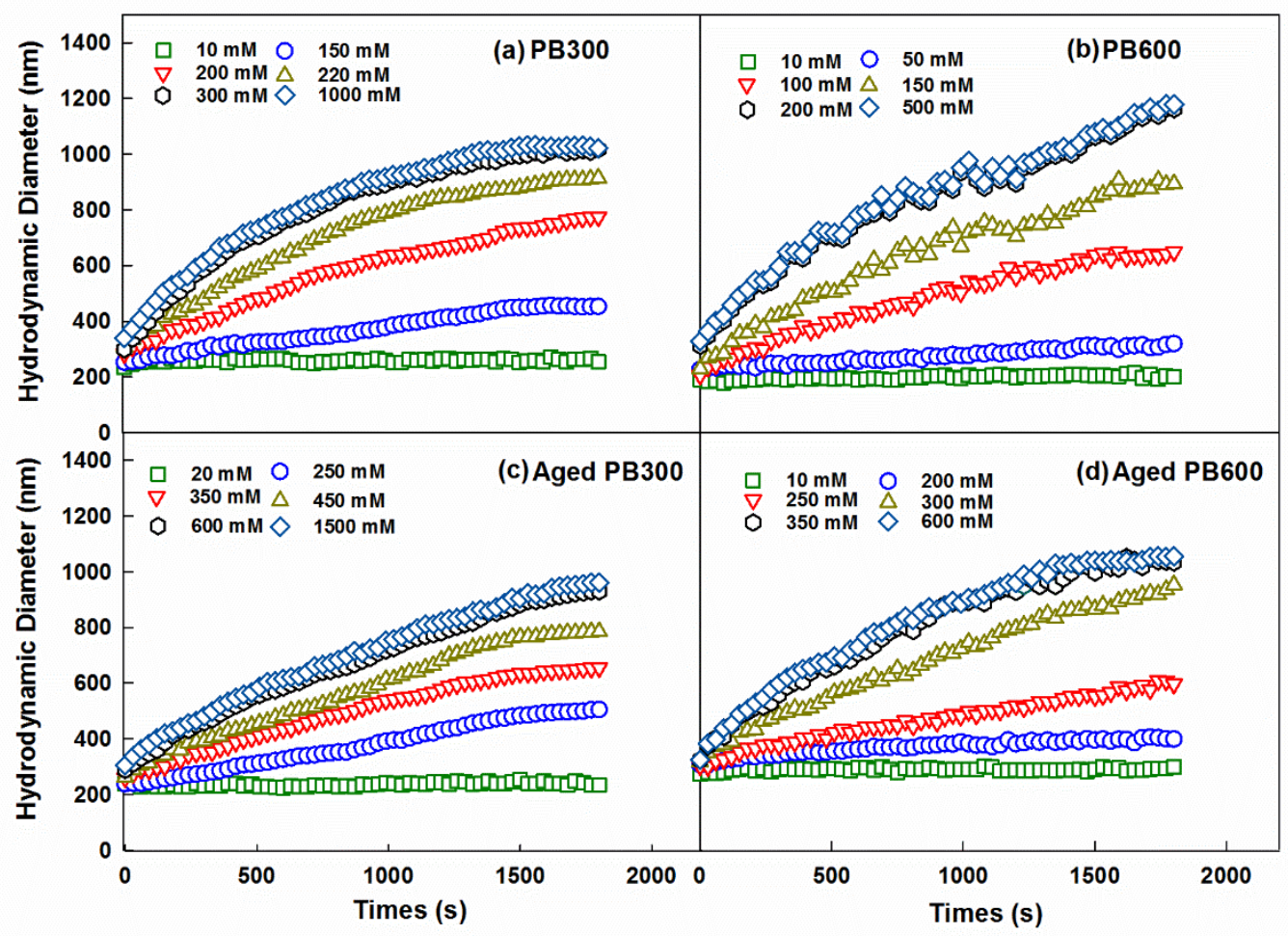

Figure S9. Aggregation profiles of pristine and aged PB300 and PB600 in $\mathrm{NaCl}$ solution at pH 6.5 (room temperature $25^{\circ} \mathrm{C}$ ). 


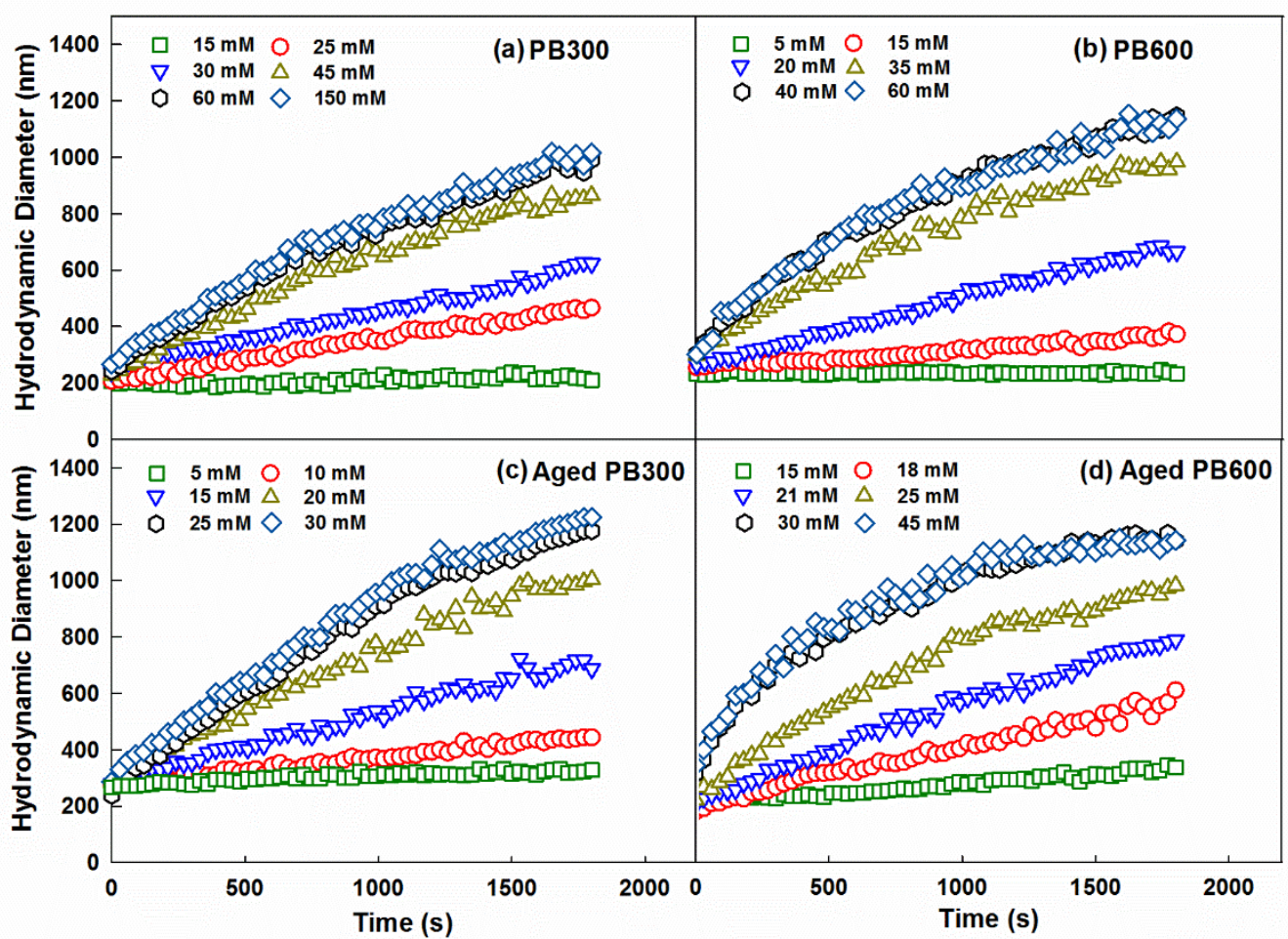

Figure S10. Aggregation profiles of pristine and aged PB300 and $\mathrm{PB} 600$ in $\mathrm{CaCl}_{2}$ solution at pH 6.5 (room temperature $25^{\circ} \mathrm{C}$ ). 

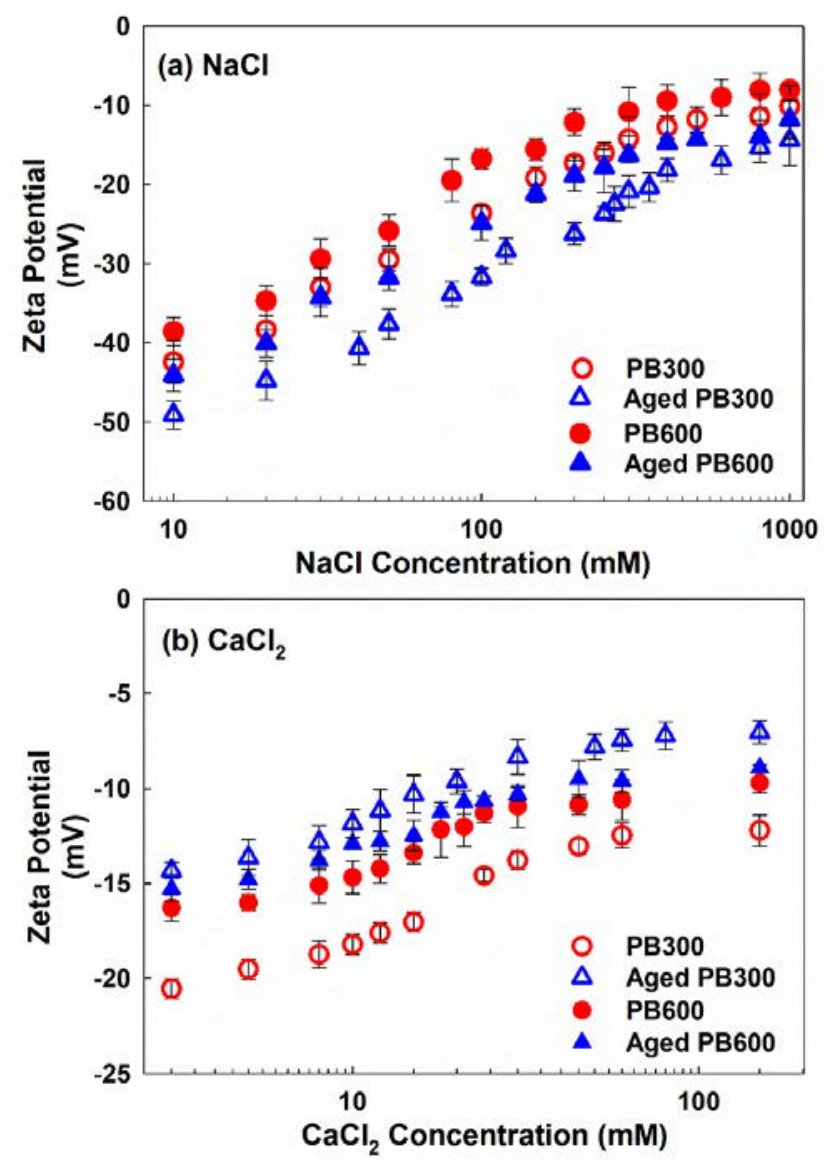

Figure S11. Zeta potential of pristine and aged PB300 and PB600 colloids as a function of (a) $\mathrm{NaCl}$ and (b) $\mathrm{CaCl}_{2}$ concentration at $\mathrm{pH}$ 6.5. Each data point was the average of triplicate samples from 20 measurements and the error bars represent standard deviations.

The zeta potentials of pristine and aged biochar colloids at different $\mathrm{NaCl}$ concentrations are compared in Figure S11a. The zeta potentials of both the pristine and aged biochar colloids became less negative with increasing $\mathrm{NaCl}$ concentrations due to charge screening at higher electrolyte concentrations. ${ }^{14,15}$ The zeta potentials of the aged biochar colloids were more negative than the pristine biochar colloids, probably due to the greater density of carboxyl groups in the aged biochar colloids (Figure 1 and Table 1). After aging, the CCCs increase in PB300 was more pronounced than that in PB600, likely due to an increase of carboxyl group by 1.54 mmol g ${ }^{-1}$ in PB300 comparing to $1.26 \mathrm{mmol} \mathrm{g}^{-1}$ in PB600 (Table 1) and subsequently greater colloidal stability of aged PB300. 


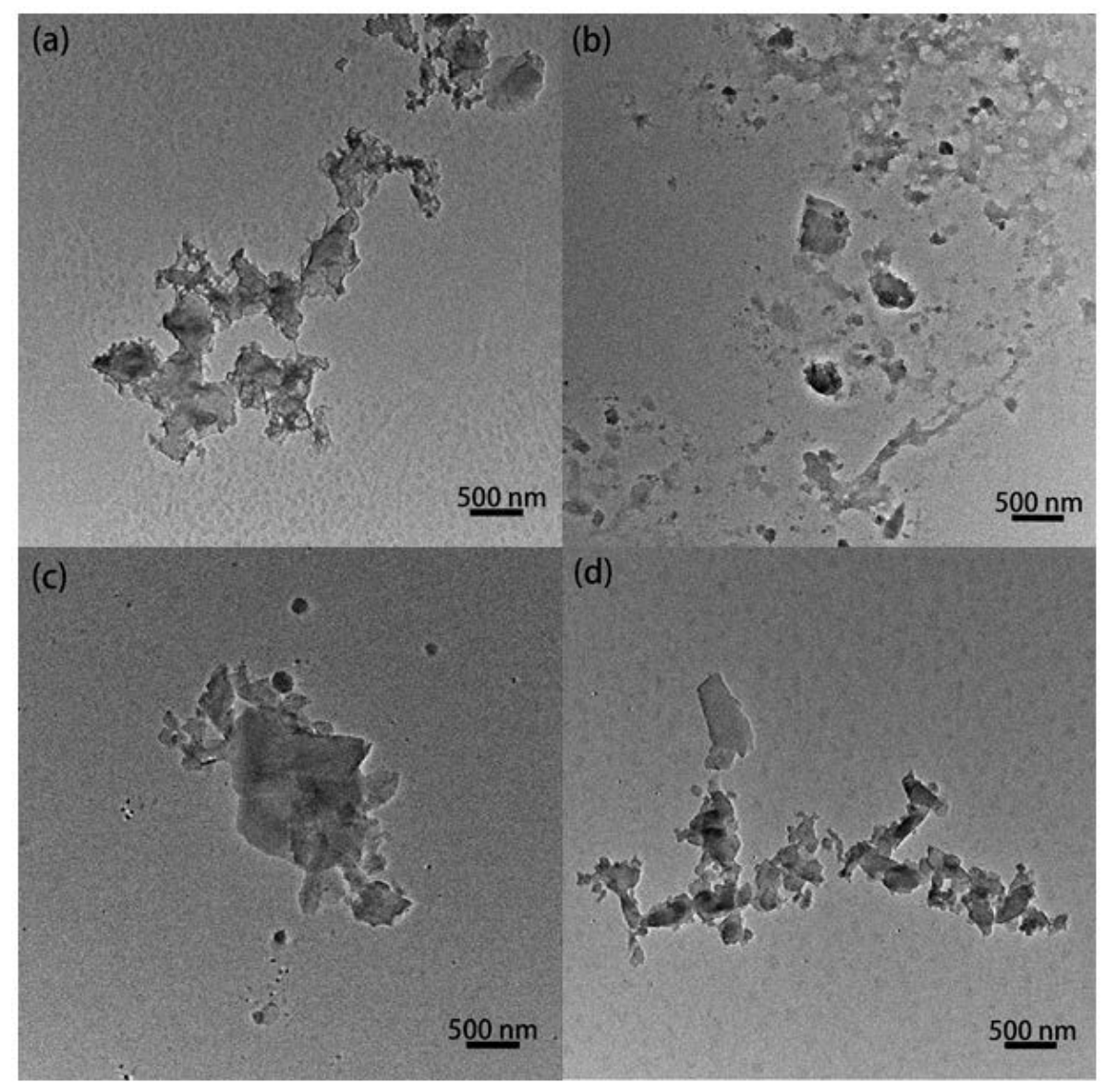

Figure S12. Representative TEM images for (a) PB300, (b) Aged PB300, (c) PB600, and (d) Aged PB600 colloids in $600 \mathrm{mM} \mathrm{NaCl}$ at pH of 6.5 . 


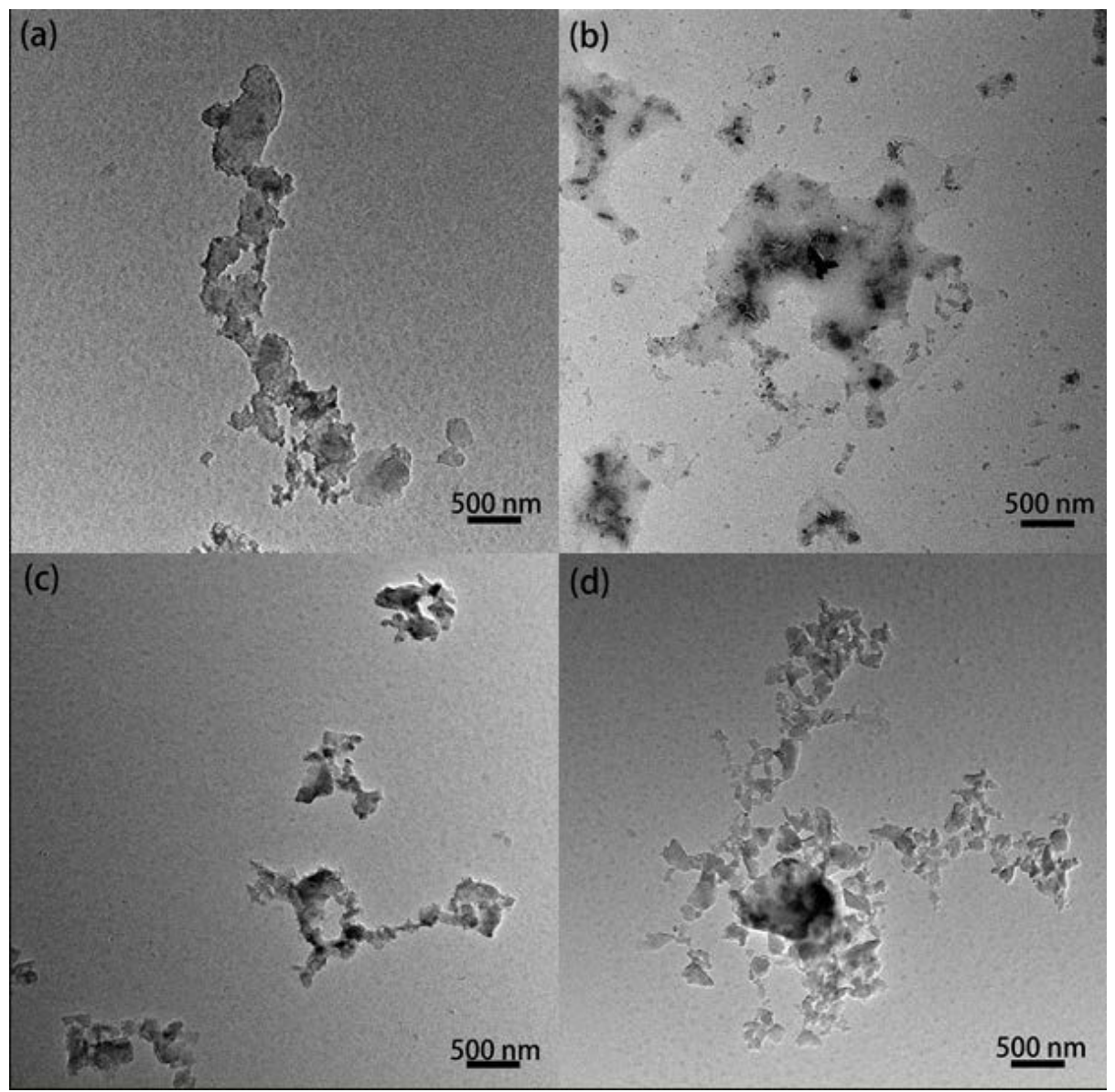

Figure S13. Representative TEM images for (a) PB300, (b) Aged PB300, (c) PB600, and (d) Aged PB600 colloids in $60 \mathrm{mM} \mathrm{CaCl}_{2}$ at $\mathrm{pH}$ of 6.5 . 

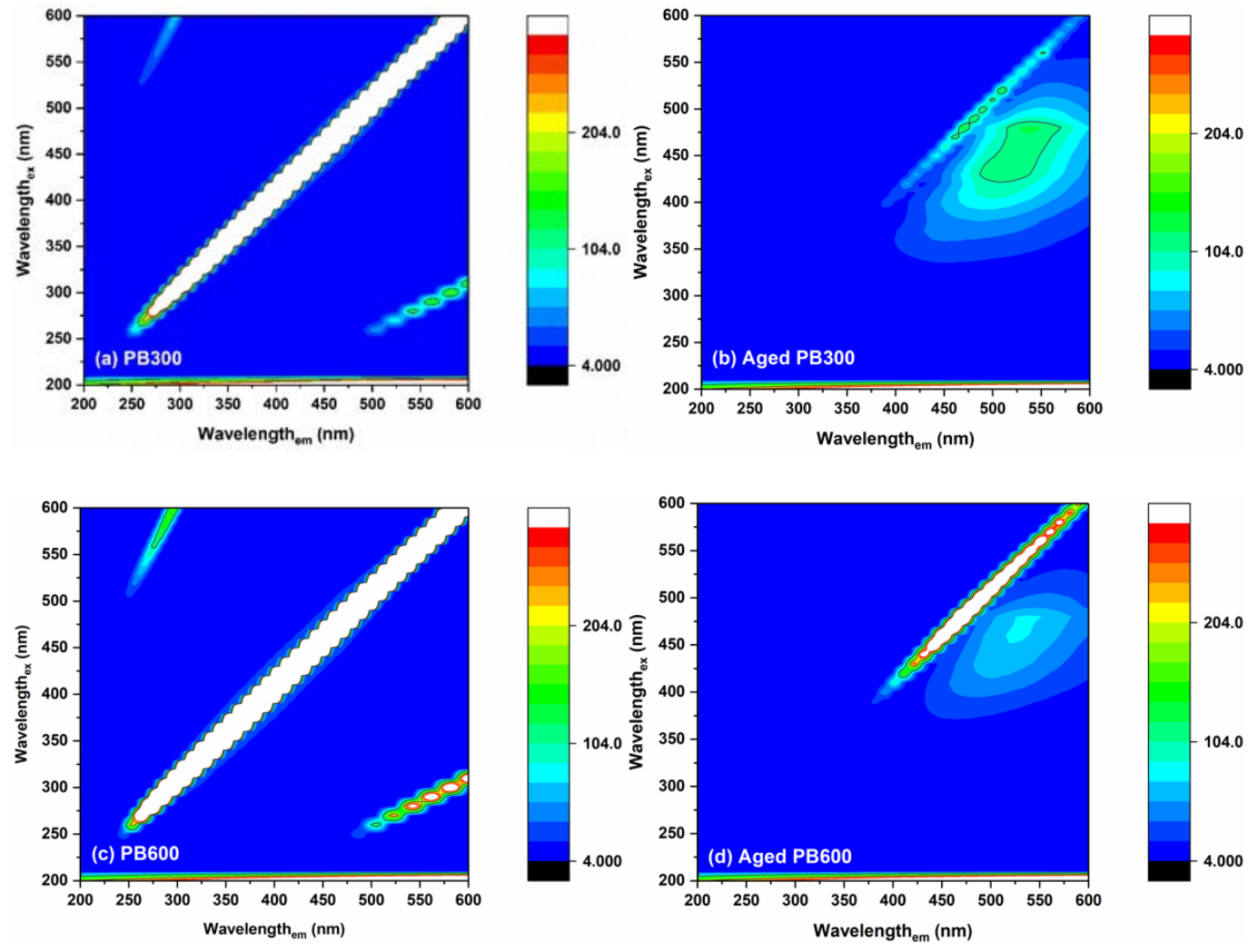

Figure S14. Fluorescence EEMs for pristine and aged biochar (Data in the areas in the top left and bottom right corners where Rayleigh scattering occurs were set to four). 


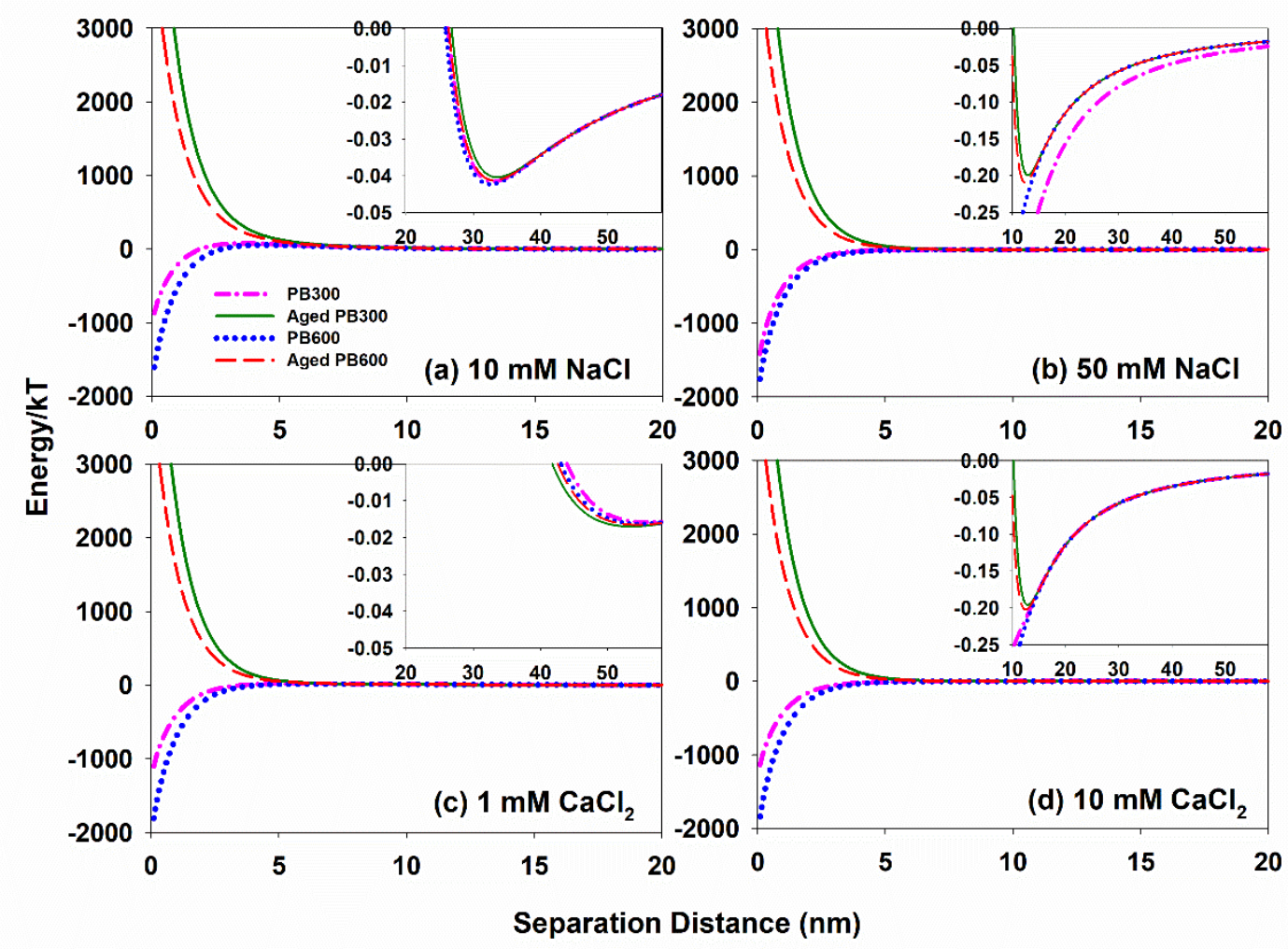

Figure S15. XDLVO interaction energy profiles for pristine and aged biochar colloids and sand interactions in $\mathrm{NaCl}$ or $\mathrm{CaCl}_{2}$ solutions respectively. 


\section{References}

(1) Bradford, S.A.; Simŭnek, J.; Bettahar, M.; Van Genuchten, M.T.; Yates, S.R. Modeling colloid attachment, straining, and exclusion in saturated porous media. Environ. Sci. Technol. 2003, 37 (10), 2242-2250.

(2) Schijven, J.F.; Simŭnek, J. Kinetic modeling of virus transport at the field scale. J. Contam. Hydrol. 2002, 55 (1), 113-135.

(3) Wang, D.J.; Zhang, W.; Hao, X.Z.; Zhou, D.M. Transport of biochar particles in saturated granular media: effects of pyrolysis temperature and particle size. Environ. Sci. Technol. 2013, 47 (2), 821-828.

(4) Adamczyk, Z.; Siwek, B.; Zembala, M.; Weronski, P. Kinetics of localized adsorption of colloid particles. Adv. Colloid Interf. Sci. 1994, 48 (94), 151-280.

(5) Johnson, P.R.; Elimelech, M. Dynamics of Colloid Deposition in Porous Media: Blocking Based on Random Sequential Adsorption. Langmuir 1996, 11(3), 801-812.

(6) Simŭnek, J.; Genuchten, M.T.V.; Šejna, M. The HYDRUS-1D Software package for simulating the movement of water, heat, and multiple solutes in variably saturated media: Version 3.0. 2005.

(7) Gregory, J. Aproximate expressions for retarded van der waals interaction. $J$. Colloid Interface Sci. 1981,83(1), 138-145.

(8) van Oss C.J. Long-range and short-range mechanisms of hydrophobic attraction and hydrophilic repulsion in specific and aspecific interactions. J. Mol Recognit. 2003, 16(4), 177-190.

(9) van Oss C.J.; Chaudhury, M.K; Good, R.J. Interfacial Lifshitz-Vanderwaals and Polar Interactions in Macroscopic Systems. Chem. Rev. 1988, 88(6), 927-941.

(10) Yang, W.; Wang, Y.; Sharma, P.; Li, B.G.; Liu, K.S.; Liu, J.; Flury, M.; Shang, J.Y. Effect of naphthalene on transport and retention of biochar colloids through saturated porous media. Coll. Surf. A: Physicochem. Eng. Asp. 2017, 530, 146-154.

(11) Xu, F.X.; Wei, C.H.; Zeng, Q.Q.; Li, X.N.; Alvarez, P.J.J.; Li, Q.L.; Qu, X.B.; Zhu, D.Q. Aggregation behavior of dissolved black carbon: implications for vertical mass flux and fractionation in aquatic systems. Environ. Sci. Technol. 2017, 51 (23), 13723-13732

(12) Qu, X.L.; Hwang, Y.S.; Alvarez, P.J.; Bouchard, D.; Li, Q.L. UV irradiation and humic acid mediate aggregation of aqueous fullerene $\left(\mathrm{nC}_{60}\right)$ nanoparticles. Environ. Sci. Technol. 2010, 44 (20), 7821-7826.

(13) Hardy, W.B. A preliminary investigation of the conditions which determine the stability of irreversible hydrosols. J. Phys. Chem. 2002, 66 (4), 110-125.

(14) Zhang, W.; Niu, J.Z.; Morales, V.L.; Chen, X.C.; Hay, A.G.; Lehmann, J.; Steenhuis, T.S. Transport and retention of biochar particles in porous media: effect of $\mathrm{pH}$, ionic strength, and particle size. Ecohydrology 2010, 3 (4), 497-508.

(15) Chen, K.L.; Elimelech, M. Relating colloidal stability of fullerene (C60) nanoparticles to nanoparticle charge and electrokinetic properties. Environ. Sci. Technol. 2009, 43 (19), 7270-7276. 